\title{
LANGMUIR-BLODGETT NANOTEMPLATE CRYSTALLIZATION COMBINED TO LASER- MICROFRAGMENTATION UNIQUELY CHARACTERIZE PROTEINS CRYSTALS BY SYNCHROTRON MICRODIFFRACTION
}

\author{
${ }^{1,2,3}$ Claudio Nicolini, ${ }^{1}$ Luca Belmonte, ${ }^{3}$ Christian Riekel, \\ ${ }^{4}$ Christian Koenig and ${ }^{1,2}$ Eugenia Pechkova \\ ${ }^{1}$ Laboratories of Nanobiotechnology and Biophysics, \\ University of Genova, Corso Europa 30, Genova, 6132, Italy \\ ${ }^{2}$ Nanoworld Institute, Fondazione ELBA Nicolini, Pradalunga, Bergamo, 24029, Italy \\ ${ }^{3}$ Experiments Division, European Synchrotron Radiation Facility, B.P.220, Grenoble Cedex, 38043, France \\ ${ }^{4}$ Paul Scherrer Institute (PSI), Villigen, 5232, Switzerland
}

Received 2013-11-04; Revised 2014-02-03; Accepted 2014-02-11

\begin{abstract}
Laser-induced microfragmentation of LB nanotemplate-induced protein crystals in glycerol solution results in distinct, coherently diffracting domains. Only crystals produced according to the Langmuir-Blodgett (LB) nanotemplate technique reveal in all four proteins being tested (lysozyme, insulin, thaumatin and ribonuclease) domains highly radiation resistant, while the crystals produced by the standard hanging drop crystallization method do not. Actually the very same laser exposure causes the disappearance of these "classical" protein crystals during the same time frame of 40 min needed for the laser cutting in all four proteins being tested. The microdiffraction of microcrystals prepered by the combination of LangmuirBlodgett and Laser technologies proves that not only the Lysozyme survives the process, as shown recently by nanodifraction, but also all three other model proteins appear to behave similarly well, namely insulin, thaumatin and ribonuclease. The result confirms the emerging of a new biophysical technique uniquely usefull for synchrotron radiation studies based on small protein microcrystals uniquely radiation resistant when prepered by LB nanotemplate and subsequently fragmented by Laser.
\end{abstract}

Keywords: Langmuir-Blodgett (LB), Force Microscopy (AFM)

\section{INTRODUCTION}

Laser-microdissection have recently (Pechkova et al., 2013; Pechkova and Nicolini, 2010) been successfully used to dissect Langmuir-Blodgett lysozyme crystals (Nicolini and Pechkova, 2006a; Pechkova et al., 2004; 2007; 2009; Belmonte et al., 2012) in order to obtain pieces of crystals of very small dimensions in conjuction with X-ray nanodiffraction techniques capable to overcome the very common problem of twinned, defect, aggregated and mosaic crystals.

Laser microfragmentation of lysozyme crystals prepered by Langmuir-Blodgett nanotemplate (needs however to be extended to other protein models, such as ribonuclease, thaumatin and insulin, all less robust than lysozyme and systematically compared with their classical counterparts (Nicolini and Pechkova, 2006b; Pechkova et al., 2004; 2007; 2009; Belmonte et al., 2012) laser dissected, in order to establish its significance and its

Corresponding Author: Claudio Nicolini, Laboratories of Nanobiotechnology and Biophysics,

University of Genova, Corso Europa 30, Genova, 6132, Italy 
general extension to protein crystallography (Nave, 1999; Pechkova and Nicolini, 2004). This is thereby the main objective of this comunication.

Several demonstration experiments show that lasermicrodissection techniques can also be applied to protein crystals (Pechkova et al., 2013; Pechkova and Nicolini, 2010). We have used the term laser-microdissection for the cutting of a crystal by a laser beam into smaller pieces (Pechkova et al., 2013) while microfragmentation is used for the separation of a microdissected crystal into smaller fragments due to effects such as cavitations at domain boundaries and solvent interpenetration.We will explore in this contribution the question whether protein crystals differing in perfection and X-ray radiation stability also differ in microdissection and microfragmentation behavior. Indeed, protein crystals grown by a LangmuirBlodgett (LB) based method (called LB-crystals) are shown here to have a unique higher radiation stability than crystals provided by standard (e.g., hanging drop) crystallization techniques (called standard-crystals) in the wide range of four quite different proteins. Atomic Force Microscopy (AFM) suggests also differences in surface topologies for protein crystals grown according to the two methods (Santucci et al., 2011).

\section{MATERIALS AND METHODS}

\subsection{Protein Crystallization by LB nanotemplate}

Utilizing an up-to-date crystallization technique (Nicolini and Pechkova, 2006a; Pechkova et al., 2004) based on Langmuir-Blodgett nanotemplate (Nicolini, 1997), crystals of four different model proteins (lysozyme, thaumatin, insulin and ribonuclease) are obtained. These crystals grown by nanostructured template (Pechkova et al., 2009) appear more radiation resistant than the classical ones, even in presence of a third-generation highly focused ID13 beamline at the European Synchrotron Radiation Facility. The electron density maps and the changes in parameters like total diffractive power, B-factor and pairwise R-factor have been discussed. Protein crystals, grown by LB nanotemplate based method, proved to be more radiation resistant compared to crystals grown by classical hanging drop method in terms of global and specific damage (Pechkova et al., 2004; 2009; Belmonte et al., 2012), both used to compare radiation damage as function of dose. As suggested earlier (Belmonte et al., 2012), three metrics are used to monitor global damage for both kinds of crystals, namely total diffracting power of crystal, Isotropic B Factor and Pairwise R Factor. Other commonly used metrics of radiation damage like mosaicity and cell volume increment were utilized even if sometimes non-predictable increase or a non-linear behavior could happen. Specific structural changes in protein exposed to high radiation dose appear to occur for these LB protein crystals with respect to the classical hanging drop crystals in reproducible way, i.e., water distribution (Pechkova et al., 2012a) and in specific sites and bonds, i.e., glutamates and aspartates and for disulphide bonds. Highly ordered, well diffracting and radiation stable crystals were confirmed for several other proteins, such as human protein kinase CK2 (Pechkova et al., 2003), Oxygen-Bound Hell's Gate Globin I (Pechkova et al., 2012a) and other model proteins (i.e., thermolysin, ribonuclease, thaumatine and insulin), which confirm the significant radiation resistance earlier reported for LB Proteinase K (Pechkova et al., 2009), LB Lysozyme (Nicolini and Pechkova, 2006b; Pechkova et al., 2004; Pechkova and Nicolini, 2004) and LB human kinase (Pechkova et al., 2003) crystals, despite occasional gloomy opinions to the contrary.

LB-nanofilms were generated by the LangmuirBlodgett (LB) technique and its variation, a modified Langmuir-Schaeffer technique (LS). Typically protein was spread at the air-water interface of an in-house LBthrough and immediately compressed with $70 \mathrm{~cm} \mathrm{~min}^{-1}$ to a surface pressure of about $20 \mathrm{mN} \mathrm{m}^{-1}$. The protein monolayers were transferred from the water surface onto siliconized cover slips by touching the support in parallel to the surface according to the LS-technique at the pressure of $20 \mathrm{mN} \mathrm{m}^{-1}$. These LB-nanofilms were used as crystallization templates (Nicolini, 1997; Pechkova et al., 2012a; 2012b; 2003). Crystallization conditions for LBand standard-crystals were both based on the hanging drop vapour diffusion method (Pechkova et al., 2012b).

\subsection{Laser-Microdissection Microfragmentation}

Experiments were performed using a Zeiss PALM laser-microdissection system with a laser wavelength of $\lambda=355 \mathrm{~nm}$ and $<2 \mathrm{~ns}$ pulses of $90 \mathrm{~J}$ each at $100 \mathrm{~Hz}$ (ZEISS, 2012). This corresponds for a $\sim 4 \mathrm{~m}^{2}$ laser spot to a laser fluency of $\sim 562 \mathrm{~J} / \mathrm{cm}^{2}$ and a flux density of $\sim 4 * 10^{21}$ photons $\mathrm{s}^{-1} \mathrm{~mm}^{-2}$. The laser beam was focused on the surface of the crystal avoiding thus shockwave induced crack formation. In order to allow in-situ observation and manipulation of cut crystals, we performed microdissection operations for all four proteins being utilized, both classical and LB, in an open aqueous solution drop rather than in a sample cell or in a flash-frozen cryoloop. The freely floating protein crystals and the convective flow induced by evaporation 
did, however, not allow clear cuts. In addition, the evaporation resulted also in salt precipitation which limited the time available for sample manipulation. The movement of crystals and fragments could, however, be significantly reduced by electrostatically fixing them to a mica sheet and using a more viscous $\sim 20 \%$ glycerol solution. This also reduces the evaporation rate and allows in principle subsequent cryocooling of the sample. This method enabled recording high quality optical images of the microdissection process and subsequent microfragmentation; based on this observation we pursued two parallel routes of investigation using both classical amd LB crystals, namely:

- For microcrystallographic characterization in the 5 $\mu \mathrm{m}$ beamsize (this manuscript) for the four chosen proteins we transfer crystal microfragments from the drop into a cryoloop for cryofreezing

- For nanocrystallographic characterization in the 0.4 $\mu \mathrm{m}$ beamsize (Pechkova et al., 2013) we cut crystals directly in a nylon cryoloop which was aligned in the laser-beam by a micromanipulator

While for Lysozyme was shown earlier (Pechkova and Nicolini, 2010), the LB microdissectected and microfragmented crystals from the three other model proteins (insulin, ribonuclease and thaumatin) are given in Fig. 1 and 2. The Thaumatine, Ribonuclease and Insulin crystals in the pictures represent microdissected LB fragments obtained in 20\% Glycerol.

20\% Glycerol solution (Pechkova et al., 2013; Pechkova and Nicolini, 2010) got several advantages over the other solutions tested before. First of all, the time for the manipulation is not limited due to the creation of salt crystals, as in a water solution. Additionally, the Protein Crystals don't float around as fast as in Water, but are free enough to move away from each other after a cut. Furthermore, the crystals are not being dissolved in the Glycerol Solution. The only disadvantage is the appearance of bubbles in the solution which will not disappear, due to the viscosity. Nevertheless, it's possible to cut small parts of a crystal and to store them for a long enough time to catch them with a loop or with kapton grid (Fig. 1).

We have catched the crystals also either with a nylon loop mounted to a piezoelectric micromanipulator or manually. The advantage over the manual fishing is, that our manipulator is very stable and precise. Nevertheless, manual fishing is sufficient for getting hold of the crystals (Fig. 1 and 2).

\subsection{Synchrotron Radiation Experiments and Data Processing}

We used the ID13 beamline at the ESRF-Grenoble (Riekel et al., 2009). Experiments were performed with a monochromatic wavelength of $\lambda=0.09611 \mathrm{~nm}$, using a beam focused by crossed linear Fresnel lenses to about 5 $\mu \mathrm{m}$ spot with a flux of $7 * 10^{10}$ photons/s. A rasterscanning goniometer with integrated air-bearing rotation axis was used. Sample supports were attached by a magnetic base to the ID13 scanning goniometer and aligned normal to the beam by an on-axis Olympus microscope, which was calibrated to the beamline focal spot. Experiments were performed in transmission geometry at $100 \mathrm{~K}$ using an Oxford Cryoflow system. Diffraction data were collected using a MAR CCD 165 detector with $1024 * 1024$ pixels at a sample-to-detector distance of $114.41 \mathrm{~mm}$ for a typical exposure time/pattern of $1 \mathrm{~s}$. The raster-diffraction experiments were analyzed with the FIT2D program (www.esrf.fr/computing/scientific/FIT2D/).

For the microcrystallographic acquisition processing and refinement were carried out as previously described (Pechkova et al., 2009; Belmonte et al., 2012) and radiation damage computed (Garman, 2010). Spacegroup $\mathrm{P}_{4} 2_{1} 2$ was recognized by POINTLESS (Evans, 2006) and all data sets were processed in this spacegroup. Dataset scaling was performed using SCALA and Freerflag from the CCP4 software package (Bailey, 1994). In order to obtain significant statistics, data were processed at high resolution. According to the Matthews coefficient results (Kantardjieff and Rupp, 2003) molecular replacement was performed with only one molecule in the asymmetric unit assuming a protein mass of $14.3 \mathrm{KDa}$. Automated molecular replacement was performed using MOLREP (Vagin and Teplyakov, 1997) and the lysozyme structure derived from thin-film-based crystals (PDB 2AUB) (Pechkova et al., 2005) as template (Berman et al., 2003). The PDB file was then refined using REFMAC5 (Murshudov et al., 1999) for both datasets. Manipulation of PDB files was performed using RASMOL (Sayle, 1995). Before the final refinement step, electron density maps were inspected by COOT (Emsley et al., 2010) at the same contour level of $0.78 \mathrm{e}$ $\AA^{-3}$ and a last refinement step was performed. Statistics of data collection, processing and refinement are shown in Table 3. Visual inspection of protein structures was performed using PyMol (2012). 


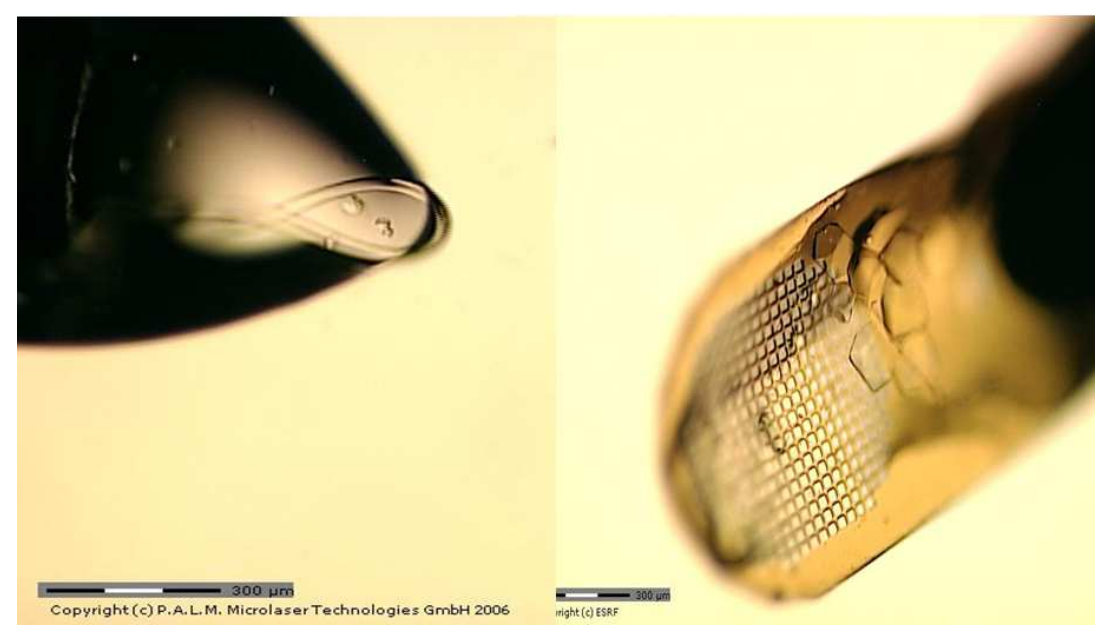

Fig. 1. Langmuir-Blodgett Protein Microcrystals obtained by laser microdiffracted, eiher of Insulin fished in the beamline loop (left) or of Ribonuclease captured in a Kapton grid (right)
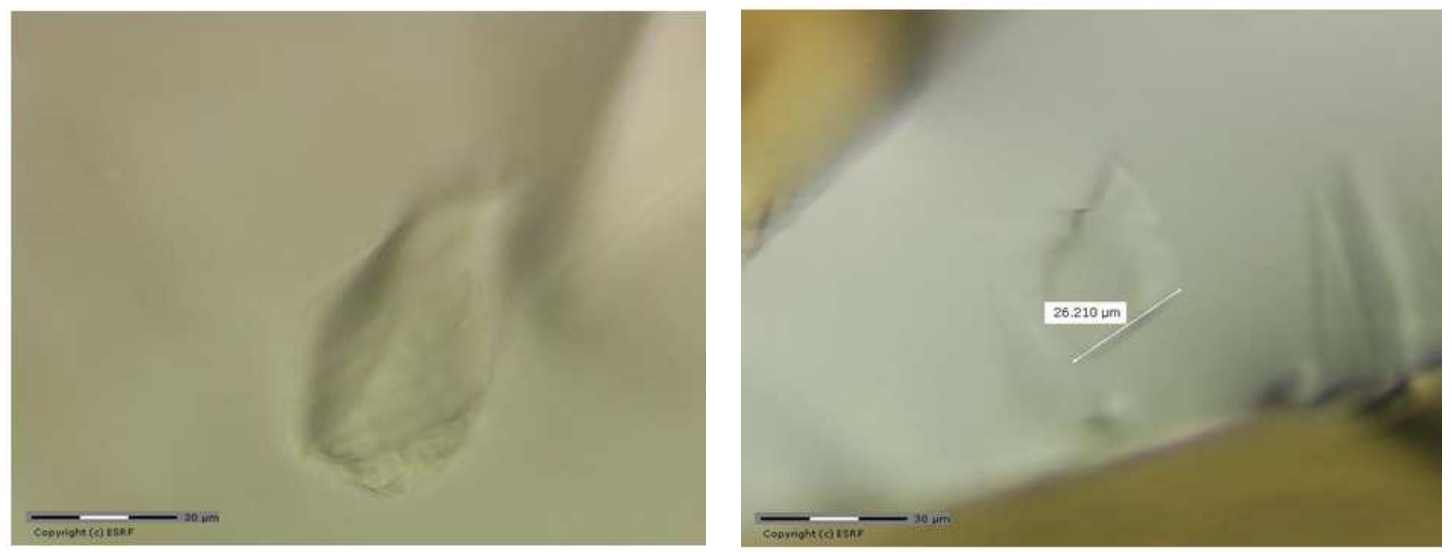

Fig. 2._Laser Microfragments of Insulin (right) and Thaumatin (left) Microcrystals prepered by Langmuir-Blodgett nanotemplate

\section{RESULTS AND DISCUSSION}

\subsection{Laser-Microfragmentation of Protein Crystals}

Table 1 summarizes the crystallization conditions for all four different proteins under hanging drop vapour diffusion either with or without LB nanotemplate.

Numerous small microcrystals have then been produced by laser cutting only on LB crystals since the classical crystals completely disappears under the same laser exposure of $40 \mathrm{~min}$. This allows to evaluate radiation damage (Garman, 2010) by synchrotron microfocussing on higly focussed ID13 beamline (5 microns beamsize) in these quite small crystals obtained as shown in Table 1 and 2 by using the same proteins utilized in the ID14/23/29 beamlines studies (Pechkova et al., 2009; Belmonte et al., 2012). Actually on the last proteins microcrystals we have applied additional continous laser expsosure which has quite larger number of photons per unit area and unit time with respect to synchrotron radiation beamlines. The laser cutting of microfragmentated crystals for all four proteins have been carried out for crystal size indicated in Table 2 in Langmuir-Blodgett crystals by laser proper exposure for $40 \mathrm{~min}$. The very same laser exposure of 40 min needed for the laser cutting of all four LB proteins being tested causes the disappearance of all "classicallyprepered" protein crystals, namely for lysozyme, thaumatin, insulin and ribonuclease. 
Claudio Nicolini et al. / American Journal of Biochemistry and Biotechnology 10 (1): 22-30, 2014

Table 1. Crystallization conditions at $\mathrm{T}=25^{\circ} \mathrm{C}$ of LB-crystals used for laser microdissection

\begin{tabular}{|c|c|c|c|}
\hline Protein & Protein solution & Reservoir & Drop \\
\hline $\begin{array}{l}\text { Lysozyme (from } \\
\text { hen egg white) }\end{array}$ & $40 \mathrm{mg} \mathrm{mL}^{-1} 50 \mathrm{mM}$ sodium acetate $\mathrm{pH} 4.5$ & $0.9 \mathrm{NaCl}$ in $50 \mathrm{mM}$ sodium acetate & $1: 1$ \\
\hline $\begin{array}{l}\text { Thaumatin (from } \\
\text { Thaumatococcus Daniellii) }\end{array}$ & $15 \mathrm{mg} \mathrm{mL}^{-1}$ in $100 \mathrm{mM}$ ADD buffer $\mathrm{pH} 6.5$ & $\begin{array}{l}1 \mathrm{M} \mathrm{Na} / \mathrm{K} \text { tartrate in } 100 \mathrm{mM} \text { ADD } \\
\text { buffer } \mathrm{pH} 6.5\end{array}$ & $1: 1$ \\
\hline $\begin{array}{l}\text { Insulin (from bovine } \\
\text { pancreas) }\end{array}$ & $\begin{array}{l}18 \mathrm{mg} \mathrm{mL}^{-1} \text { in } 50 \mathrm{mM} \mathrm{Na} \mathrm{HPO}_{4} \\
\text { pH } 10.41 \mathrm{mM} \text { EDTA }\end{array}$ & $\begin{array}{l}400 \mathrm{mM} \mathrm{Na}_{2} \mathrm{HPO}_{4} \mathrm{pH} 10.410 \\
\text { mM EDTA }\end{array}$ & $1: 1$ \\
\hline Ribonuclease & $10 \mathrm{mg} \mathrm{mL}^{-1}$ in $50 \mathrm{mM}$ Na-acetate $\mathrm{pH} 5.5$ & $\begin{array}{l}1.75 \mathrm{M}\left(\mathrm{NH}_{4}\right)_{2} \mathrm{SO}_{4} 2 \mathrm{M} \mathrm{NaCl} \\
\text { in } 100 \mathrm{mM} \mathrm{Na} \text {-acetate } \mathrm{pH} 5.5\end{array}$ & $1: 1$ \\
\hline
\end{tabular}

Table 2. LB-induced Protein Microcrystals obtained by Laser microdissection and microfragmentation

\begin{tabular}{lllc}
\hline Protein & Crystal Size(micron^2) & Beamsize (Microns) & $\begin{array}{l}\text { Number of Images per } \\
\text { Dataset at } 1^{\circ} \text { of rotation }\end{array}$ \\
\hline Thaumatin & $10 \times 30$ & 5 & 82 \\
Insulin & $10 \times 26$ & 5 & 90 \\
Ribonuclease & $30 \times 22$ & 5 & 122 \\
Lysozyme & $10 \times 30$ & 5 & 38 \\
\hline
\end{tabular}

\subsection{X-ray Microdiffraction of Microfragmented LB-Crystals}

In the lst column of Table $\mathbf{2}$ are indicated the number of diffraction images acquired from each protein microcrystals. According to the Matthews coefficient results molecular replacement was performed with only one molecule in the asymmetric unit assuming a protein mass of $14.3 \mathrm{KDa}$ for Lysozyme, 22.22 KDa for Thaumatin, 5.733 KDa for Insulin and 13.7 KDa for Ribonuclease. Automated molecular replacement was performed using MOLREP (Vagin and Teplyakov, 1997) using PDB templates with the following Ids: 2AUB for Lysozyme, 4DJ0 for Thaumatin, 4I5Z for Insulin and 3I6F for Ribonuclease as template. The PDB files were then refined using REFMAC5 (Murshudov et al., 1999) for all datasets. Before the final refinement step, electron density maps were inspected by COOT (Emsley et al., 2010) at the same contour level. Statistics of data collection, processing and refinement are shown in Table $\mathbf{1}$. Absorbed dose calculation was performed using RADDOSE (Murray et al., 2004) assuming beam energy of $12.9 \mathrm{KeV}, \lambda=0.0961 \AA$, beamsize of $5 \times 5 \mu \mathrm{m}^{2}$, exposure time of $1 \mathrm{~s}$ and a flux of about $7 * 1010$ photons $/ \mathrm{s}$ corresponding to a flux density of about $3 * 1011 \mathrm{ph} / \mathrm{s} / \mu \mathrm{m} 2$, other parameters are shown in Table 3 .

Image acquisition (Fig. 4) agrees with the minimum number of images needed for data completeness and symmetry, e.g., for a spacegroup $\mathrm{P}$ 41212 (point group 422) found for thaumatin more than 45 images were acquired. Despite to this latter sentence spacegroup recognition was difficult and not obvious in all the so far discussed laser-fragmented protein crystals with the microfocused beam. This is probably due to a very low number of diffraction patterns with a good number of high I/sigma spot. Anyway, even after laser cutting a lots of diffraction patterns could be still acquired and the very difficult solving task could be avoided with ad hoc techniques for microdissected crystals acquisition; indeed, as shown in Fig. 3 excellent diffraction patterns were acquired for thaumatin and insulin, proving the principle of laser macrofragmentation in all four protein being studied.

The radiation dose and the comparable crystallographic parameters are computed for both synchrrotron and laser assuming beam flux density of $2 \times 1013$ photons $\mu \mathrm{m}-2 \mathrm{~s}-1$ and Energy of $12.7 \mathrm{KeV}$. Dose calculation is made by the following equation:

$$
\mathrm{D}(\text { Gray })=\mu \mathrm{EtI} 0
$$

Where:

$\mu=$ Mass absorption coefficient $(\mathrm{cm} 2 / \mathrm{g})$

$\mathrm{E}=$ Energy of the X-ray $(\mathrm{KeV})$

$\mathrm{t}=$ Time of exposure (seconds)

$\mathrm{I} 0=$ Flux of the X-ray beam (photons $/ \mathrm{s} / \mathrm{nm} 2$ )

The estimate of total dose was computed using the program RADDOSE (Murray et al., 2004). 


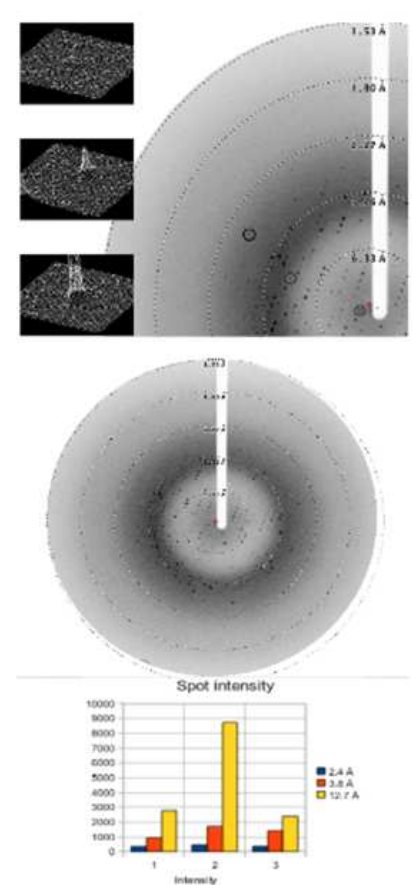

(a)
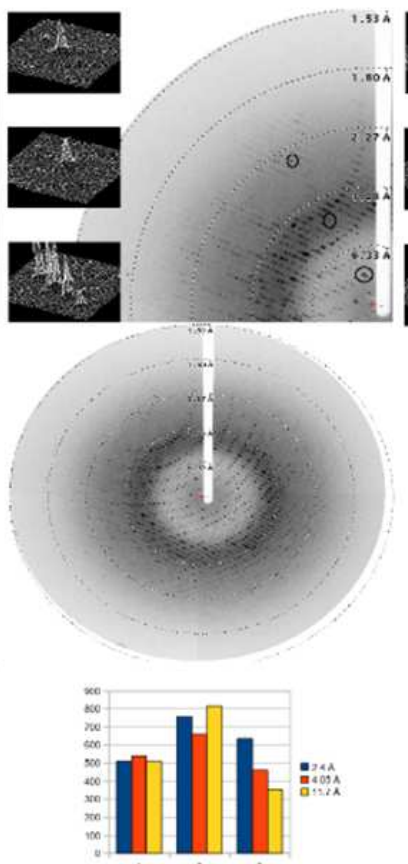

(b)
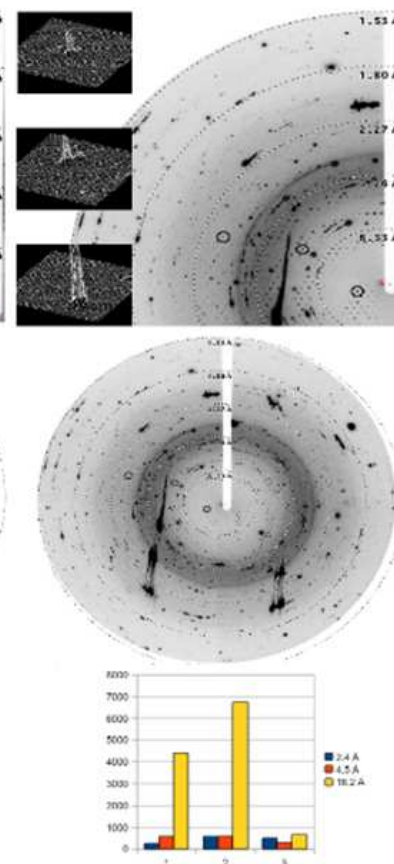

(c)
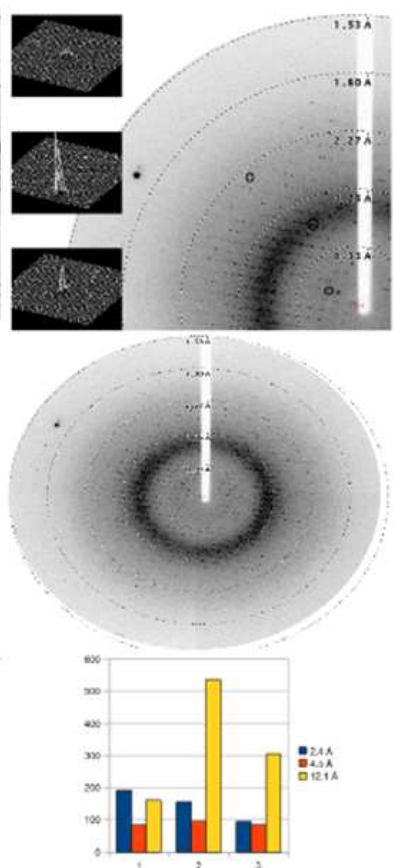

(d)

Fig. 3. Resolution rings (above) and their relative signal intensity of the reflection corresponding to identified different shell of progressive higher resolution (middle) for a diffraction pattern of laser microdissected insulin (a), thaumatin (b), ribonuclease (c) and lysozyme (d) crystals induced by LB nanotemplate vapour diffusion method; (below) Histogram of microcrystal spot intensity at $2.4,3.8$ and $12.7 \AA$ resolution for Insulin LB (left), 2.4, 4.05 and $11.7 \AA$ for thaumatin LB (center) 2.4, 4.5 and $16.2 \AA$ for LB ribonuclease (right)
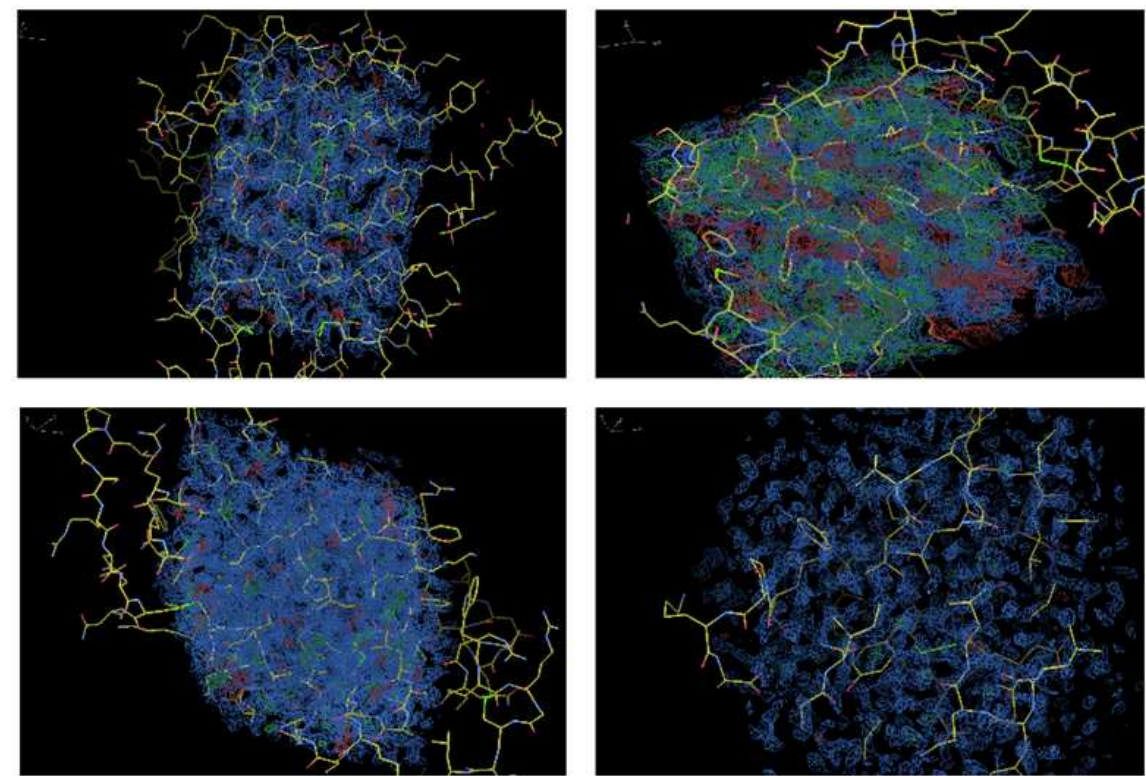

Fig. 4. Electron Density map from upper corner left clockwise Thaumatin, Ribonuclease, Insulin, Lysozyme microcrystals laser dissected. Statistics are shown in Table 2 
Table 3. Statistics for microdissected LB crystals acquired with microfocus on ESRF ID13.

\begin{tabular}{lllll}
\hline Parameters & Insulin & Thaumatin & Ribonuclease & Lysozyme \\
\hline Resolution $(\AA)$ & $1.39-18.26$ & $1.98-45.34$ & $2.37-48.92$ & $1.57-38.29$ \\
Unit cell a,b,c $(\AA)$ & 77.4977 .4977 .49 & $103.2,103.2,151.4$ & $106.71,116.31,234.9$ & 95.5638 .29109 .89 \\
$\alpha, \beta, \gamma)\left({ }^{\circ}\right)$ & 909090 & 909090 & $94.24,98.05,103.22$ & 90109.6490 \\
Spacegroup & $\mathrm{I} 213$ & $\mathrm{P} 41212$ & $\mathrm{P} 1$ & $\mathrm{P} 121$ \\
Mosaicity $\left(^{\circ}\right)$ & 1.127 & 0.567 & 0.454 & 0.885 \\
$\mathrm{R}_{\text {-factor }}$ & 0.6 & 0.36 & 0.5 & 0.4 \\
$\mathrm{R}_{\text {free }}$ & 0.63 & 0.42 & 0.5 & 0.43 \\
$\mathrm{I} / \sigma$ & 0.48 & 0.21 & 0.23 & 0.1 \\
Completeness\% & 77.82 & 85.22 & 55.56 & 26.83 \\
Total number of reflections & 11629 & 46874 & 239805 & 26802 \\
Mean B-value for side chains & 2.0 & 2.0 & 2.0 & 2.0 \\
R.m.s. on bond length $(\AA)$ & 0.012 & 0.015 & 0.027 & 0.01 \\
R.m.s. in bond angle $\left({ }^{\circ}\right)$ & 1.543 & 1.640 & 2.652 & 1.449 \\
$\mathrm{~N}^{\circ}$ of water mol & 1213 & 1213 & 33 & 559 \\
\hline
\end{tabular}

Table 4. Absorbed dose for microdissected crystals acquired with microfocus and nanofocus and for laser microdissected crystals

\begin{tabular}{lll}
\hline Protein crystal & $\begin{array}{l}\text { Absorbed Dose }(\mathrm{Gy}) \text { for } \\
\text { laser microdissected crystals }\end{array}$ & $\begin{array}{l}\text { Absorbed Dose (Gy) for microdissected crystals } \\
\text { acquired with microfocus and nanofocus }\end{array}$ \\
\hline Thaumatin & $0.331 * 10^{19}$ & $0.668 * 10^{8}$ \\
Ribonuclease & $0.52 * 10^{19}$ & $0.108 * 10^{9}$ \\
Insulin & $0.368 * 10^{19}$ & $0.748 * 10^{8}$ \\
Lysozyme & $0.141 * 10^{19}$ & $0.272 * 10^{8}$ \\
\hline
\end{tabular}

\section{CONCLUSION}

Results of radiation dose calculation are shown in Table 4, where it become readily apparent the enormous increase in the absorbed radiation dose with the laserinduced microdissection which explain the disappearance of "classical" protein crystals in all four cases and makes more striking the effect of LB nanotemplate in dramatically enhancing radiation stability. Radiation damage limits the highest resolution data collection on a single spot, as is indeed conclusively shown in a native globin protein crystal recently solved (Pechkova et al., 2012b) and in model proteins using submicron Grazing Incidence Small Angle Scattering (Pechkova and Nicolini, 2011; Pechkova et al., 2010; Gebhardt et al., 2010). Overall analysis indicates more damage suffered by the classical crystals than the LB ones. By taking into account what so far discussed, LB crystals confirm the greater radiation- resistance on both global and specific damage side (Belmonte et al., 2012; Pechkova et al., 2012a; Murshudov et al., 1999). The suggestion for a possible reason for the radiation resistance of the LB-based crystal has been raised recently (Pechkova et al., 2012a) in terms of the dehydration observed to lead to better ordered protein crystals and to the significantly improved diffraction limit (Heras et al., 2003; Kuo et al., 2003; Nicolini and Pechkova, 2006a).
A fundamental clue of the unique physical-chemical properties and features of Langmuir-Blodgett crystals derives from the very recent collection of sophisticated studies down to the nanoscale (Pechkova et al., 2013; Pechkova and Nicolini, 2010). However the main efforts of LB-based crystallization should be addressed in the future mainly to overcome the barriers in membrane protein structures determination still existing (Nicolini and Pechkova, 2006b) despite all gigantic efforts.

\subsection{Supporting Material}

The atomic coordinates and structural factors have been deposited in the Protein Data Bank (www.pdb.org). LB1: RCSB ID code is RCSB074134; PDB ID code 4GFZ; LB2: RCSB ID code is RCSB074135; PDB ID code 4GG0

\section{AKNOWLEDGEMENT}

We thank Dr. ISnigireva of the ESRF microimaging laboratory for help with the use of the PALM MicroBeam microdissection system. We thank Dr. M. Burghammer for instrumental support at the ID13 beamline. This study was supported by FIRB-MIUR grants to Claudio Nicolini of the University of Genoa for Functional Proteomics (RBNE01X3CE) and for Nanosensors (RBPR05JH2P) and by a MIUR grant to the Fondazione El.B.A. for "Funzionamento" (DM48527). 


\section{REFERENCES}

Bailey, S., 1994. The CCP4 suite: Programs for protein crystallography. Acta Cryst. D, 50: 760-763. DOI: 10.1107/S0907444994003112

Belmonte, L., E. Pechkova, S. Tripathi, D. Scudieri and C. Nicolini, 2012. Langmuir-blodgett nanotemplate and radiation resistance in protein crystals: State of the art. Crit. Rev. Eukaryot. Express., 22: 211-224. PMID: 23140163

Berman, H., K. Henrick and H. Nakamura, 2003. Announcing the worldwide protein data bank. Nat. Struct. Biol., 10: 980-980. DOI: 10.1038/nsb1203980

Emsley, P., B. Lohkamp, W.G. Scott and K. Cowtan, 2010. Features and development of Coot. Acta Cryst. D, 66: 486-501. DOI: 10.1107/S0907444910007493

Evans, P., 2006. Scaling and assessment of data quality. Acta Cryst. D, 62: 72-82. DOI: 10.1107/S0907444905036693

Garman, E., 2010. Radiation damage in macromolecular crystallography: What is it and why should we care? Acta Cryst. D, 66: 339-351. PMID: 20382986

Gebhardt, R., E. Pechkova, C. Riekel and C. Nicolini, 2010. In Situ $\mu$ GISAXS: II. Thaumatin crystal growth kinetic. Biophys. J., 99: 1262-1267. DOI: 10.1016/j.bpj.2010.03.068

Heras, B., M.A. Edeling, K.A. Byriel, A. Jones and S. Raina et al., 2003. Dehydration converts DsbG crystal diffraction from low to high resolution. Structure, 11: 139-145. DOI: 10.1016/S09692126(03)00005-4

Kantardjieff, K.A. and B. Rupp, 2003. Matthews coefficient probabilities: Improved estimates for unit cell contents of proteins, DNA and protein-nucleic acid complex crystals. Protein Sci., 12: 1865-1871. DOI: 10.1110/ps.0350503

Kuo, A., M.W. Bowler, J. Zimmer, J.F. Antcliff and D.A. Doyle, 2003. Increasing the diffraction limit and internal order of a membrane protein crystal by dehydration. J. Struct. Biol., 141: 97-102. DOI: 10.1016/S1047-8477(02)00633-0

Murray, J.W., E.F. Garman and R.B.G. Ravelli, 2004. Xray absorption by macromolecular crystals: The effects of wavelength and crystal composition on absorbed dose. J. Applied Cryst., 37: 513-22. DOI: 10.1107/S0021889804010660
Murshudov, G.N., A.A. Vagin, A. Lebedev, K.S. Wilson and E.J. Dodson, 1999. Efficient anisotropic refinement of macromolecular structures using FFT. Acta Cryst. D, 55: 247-255. DOI: 10.1107/S090744499801405X

Nave, C., 1999. Matching X-ray source, optics and detectors to protein crystallography requirements. Acta Cryst. D, 55: 1663-1668. DOI: 10.1107/S0907444999008380

Nicolini, C. and E. Pechkova, 2006a. Nanostructured biofilms and biocrystals. J. Nanosci. Nanotechnol., 6: 2209-2236. DOI: 10.1166/jnn.2006.502

Nicolini, C. and E. Pechkova, 2006b. Structure and growth of ultrasmall protein microcrystals by synchrotron radiation: I. $\mu$ GISAXS and $\mu$ diffraction of P450scc. J. Cell. Biochem., 97: 544-552. DOI: 10.1002/jcb.20537

Nicolini, C., 1997. Protein-monolayer engineering: Principles and application to biocatalysis. Trends Biotechnol., 15: 395-401. DOI: 10.1016/S01677799(97)01084-6

Pechkova, E. and C. Nicolini, 2004. Protein nanocrystallography: A new approach to structural proteomics. Trends Biotechnol., 22: 117-122. DOI: 10.1016/j.tibtech.2004.01.011

Pechkova, E. and C. Nicolini, 2010. Domain organization and properties of LB lysozyme crystals down to submicron size. Anticancer Res., 30:27452748. PMID: 20683008

Pechkova, E. and C. Nicolini, 2011. In situ study of nanotemplate-induced growth of lysozyme microcrystals by submicron GISAXS. J. Synchrot. Radiat., 18: 287-292.

Pechkova, E., G. Tropriano, C. Riekel and C. Nicolini, 2004. Radiation stability of protein crystals grown by nanostructured templates: Synchrotron microfocus analysis. Spectrocheminica Acta B, 59: 1687-1693. DOI: 10.1016/j.sab.2004.07.020

Pechkova, E., G. Zanotti and C. Nicolini, 2003. Threedimensional atomic structure of a catalytic subunit mutant of human protein kinase CK2. Acta Cryst. D, 59: 2133-2139. DOI: 10.1107/S0907444903018900

Pechkova, E., L. Belmonte, C. Riekel, D. Popovd and C. Koenige et al., 2013. Laser-microdissection of protein crystals down to submicron dimensions. J. Nanomedicine Nanotechnol.

Pechkova, E., M. Sartore, L. Giacomelli and C. Nicolini, 2007. Atomic force microscopy of protein films and crystals. Rev. Scient. Instruments, 78: 093704093704. PMID: 17902952 
Pechkova, E., R. Gebhardt, C. Riekel and C. Nicolini, 2010. In situ $\mu$ GISAXS: I. Experimental setup for submicron study of protein nucleation and growth. Biophys. J., 99: 1256-1261. DOI: 10.1016/j.bpj.2010.03.069

Pechkova, E., S. Tripathi, R.B.G. Ravelli, S. McSweeney and C. Nicolini, 2009. Radiation stability of proteinase $\mathrm{K}$ crystals grown by $\mathrm{LB}$ nanotemplate method. J. Struct. Biol., 168: 409-418. DOI: 10.1016/j.jsb.2009.08.005

Pechkova, E., V. Sivozhelezov, G. Tropiano, S. Fiordoro and C. Nicolini, 2005. Comparison of lysozyme structures derived from thin-film-based and classical crystals. Acta Cryst. D, 61: 803-808. DOI: 10.1107/S0907444905006578

Pechkova, E., V. Sivozhelezov, L. Belmonte and C. Nicolini, 2012a. Unique water distribution of Langmuir-blodgett versus classical crystals. J. Struct. Biol., 180: 57-64. DOI: 10.1016/j.jsb.2012.05.021

Pechkova, E., D. Scudieri, L. Belmonte and C. Nicolini, 2012b. Oxygen-bound hell's gate globin I by classical versus LB nanotemplate method. J. Cellular Biochem., 113: 2543-2548. DOI: 10.1002/jcb.24131

PyMol, 2012. The PyMOL Molecular Graphics System, Schrödinger, LLC. L. Schrödinger, editor. Schrödinger, LLC.
Riekel, C., M. Burghammer, R. Davies, R. Gebhardt and D. Popov, 2009. Fundaments of Soft Condensed Matter Scattering and Diffraction with Microfocus Techniques. In: Applications of Synchrotron Light to Scattering and Diffraction in Materials Life Sciences, Ezquerra, T.A., M. Garcia-Gutierrez, A. Nogales and M. Gomez (Eds.), Springer, Heidelberg, ISBN-10: 354095967X, pp: 91-104.

Santucci, S.C., D. Cojoc, H. Amenitsch, B. Marmiroli and B. Sartori et al., 2011. Optical tweezers for synchrotron radiation probing of trapped biological and soft matter objects in aqueous environments. Analyt. Chem., 83: 4863-4870. DOI: 10.1021/ac200515x

Sayle, R.A., 1995. RASMOL: Biomolecular graphics for all. Trends Biochem. Sci., 20: 374-376. DOI: 10.1016/S0968-0004(00)89080-5

Vagin, A. and A. Teplyakov, 1997. MOLREP: An automated program for molecular replacement. J. Applied Cryst., 30: 1022-1025. DOI: 10.1107/S0021889897006766

ZEISS, 2012. Laser microdissection and optical tweezers. Zeiss. 